\title{
Comparison of acute proton, photon, and low-dose priming effects on genes associated with extracellular matrix and adhesion molecules in the lungs
}

\author{
Jian Tian ${ }^{1,3^{*}}$, Sisi $\operatorname{Tian}^{2}$ and Daila S Gridley ${ }^{1+}$
}

\begin{abstract}
Background: Crew members on space missions inevitably are exposed to low background radiation and can receive much higher doses during solar particle events (SPE) that consist primarily of protons. Ionizing radiation could cause lung pathologies. Cell adhesion molecules (CAM) are believed to participate in fibrogenesis. Interactions between CAM and extracellular matrix (ECM) affect epithelial repair mechanisms in the lung. However, there are very limited data on biological effects of protons on normal lung tissue. Numerous reports have shown that exposure to low-dose/low-dose-rate (LDR) radiation can result in radioadaptation that renders cells more resistant to subsequent acute radiation. The goal of this study was to compare expression of genes associated with ECM and CAM, as well as critical profibrotic mediators, in mouse lungs after acute irradiation with photons and protons, and also determine whether pre-exposure to LDR $\gamma$-rays induces an adaptive effect.
\end{abstract}

Results: Overall, a marked difference was present in the proton vs. photon groups in gene expression. When compared to $0 \mathrm{~Gy}$, more genes were affected by protons than by photons at both time points (11 vs. 6 on day 21 and 14 vs. 8 on day 56), and all genes affected by protons were upregulated. Many genes were modulated by LDR Y-rays when combined with photons or protons. Col1a1, $\mathrm{mmp} 14$, and $m m p 15$ were significantly upregulated by all radiation regimens on day 21 . Similarly, the change in expression of profibrotic proteins was also detected after acute and combination irradiation.

Conclusion: These data show that marked differences were present between acutely delivered protons and photons in modulating genes, and the effect of protons was more profound than that of photons. Pre-exposure to LDR $\gamma$-rays 'normalized' some genes that were modified by acute irradiation.

\section{Background}

Ionizing radiation (IR) includes photons, small packets of energy that carry electromagnetic radiation, as well as particle radiations such as protons. Among the forms of photon radiation, $\gamma$-rays have the smallest wavelength and the most energy of any other wave in the electromagnetic spectrum. In contrast, protons are subatomic particles with an electric charge of +1 and have greater biological

\footnotetext{
* Correspondence: jacktian12@gmail.com

${ }^{\dagger}$ Equal contributors

'Department of Radiation Medicine, Radiation Research Laboratories and Department of Basic Sciences, Loma Linda University, Loma Linda, California, USA

${ }^{3}$ Department of Pathological Anatomy, Nantong University, Nantong, China Full list of author information is available at the end of the article
}

impact compared to photons [1]. Virtually all forms of radiation are of concern to the National Aeronautics and Space Administration (NASA). Crew members on space missions are routinely exposed to low dose background radiation that is more than 150 times greater than on Earth [2] and are at risk for much higher doses during a solar particle event (SPE) that consists primarily of proton radiation [3]. Thus far, pulmonary abnormalities noted in astronauts have been attributed primarily to microgravity $[4,5]$; risk for lung complications associated with spacerelevant radiation are unknown. There have been essentially no investigations that directly compare acute proton and photon effects on normal lung tissue and possible modification of the outcome due to low-dose/low-dose- 
rate (LDR) $\gamma$-ray pre-exposure. Better understanding of radiation effects on normal lung tissue also has relevance in the clinical setting. Unfortunately, patients who receive radiotherapy for lung cancer develop side effects such as inflammation and sometimes even fibrosis [6,7]. Protons, however, can be delivered to the tumor at a higher dose, while reducing the dose to normal tissue [8]. The physical advantage of a proton beam compared to conventional radiotherapy (X-rays) is that the beam can be modulated to deliver most of the dose to the intended target, that is, at the peak of the Bragg curve. With conventional radiation, the maximum dose is delivered within a few centimeters of the skin surface proximal to the target. Hence, proton radiation continues to be used with increasing frequency for the treatment of patients, including those with lung cancer [9].

The lungs are among the most radiosensitive organs in the body. Our previous investigations have shown that acute photon delivery resulted in profibrotic changes in the lungs of mice [10]. Lung repair is initiated immediately following injury and includes an acute inflammatory response, cytokine and growth factor release, activation of localized stem cells, and cell-cell and cell-matrix interactions mediated through cell adhesion molecules (CAM) [11]. Radiation-induced lung fibrosis (RILF), a major late effect of photon radiation damage [12], is characterized by loss of epithelia and excessive deposition of collagen and other extracellular matrix (ECM) components. CAM is believed to participate in fibrogenesis since relatively abundant CAM proteins and re-regulated mRNAs are detected in specimens of pulmonary fibrosis [13,14]. CAM-mediated adhesive interactions that may be involved in the pathogenesis include cell-ECM and cell-cell interactions that are mediated through several CAM families, including the integrins, cadherins, selectins, and members of the immunoglobulin superfamily. Therefore, stable adhesion during these interactions is essential for adequate cell communication, epithelial integrity, and ECM homeostasis.

Several evidences have shown that transforming growth factor (TGF)- $\beta$ plays a primary role in the fibrotic process. During fibrogenesis, epithelial cells lose their characteristic markers such as E-cadherin responsible for their adhesion, and the expression of $\alpha$-smooth muscle actin (SMA), a myofibroblast marker capable of producing abundant collagen and other ECM molecules [15,16], and Slug are enhanced. Slug (Snail 2) acts as a repressor of E-cadherin $[17,18]$. However, whether the expression of these markers for fibrogenesis are affected by protons or combination of irradiation with LDR- $\gamma$ rays has not been identified to date.

Interestingly, an increasing number of studies have shown that exposure to low-dose radiation can result in radioadaptation that can be beneficial in that it renders cells more resistant to a subsequent acute radiation event, as well as more resistant to cancer and certain other pathologies $[19,20]$. The existence of this phenomenon, however, remains controversial. Thus, the overall focus of the present study was on lung parameters that may be altered due to excessive radiation exposure in the spaceflight environment, as well as nuclear/ radiological events on Earth. Expression profiles of genes that are especially important in regeneration and remodeling of lung tissue after acute proton and photon irradiation were compared, both with and without pre-exposure to LDR $\gamma$-rays. In addition, protein profiles of a critical profibrotic cytokine and three markers for fibrogenesis were also compared between irradiated groups and the 0 Gray (Gy) control. The selection of day 21 postirradiation rather than earlier time points was based in part on the premise that long-term changes in gene and protein expression patterns may have greater healthrelated significance than short-term changes that may simply be due to transient efforts to regain homeostasis. Day 56 was selected as the second time point to determine if the modulations observed in the lungs on day 21 were persistent. The present study is the first to investigate ECM and CAM response in the lungs under the conditions used.

\section{Results}

\section{Histopathology}

The histological appearance of lung tissue from control and LDR groups did not show marked abnormalities after staining with H\&E. However, epithelial hyperplasia in bronchioles appeared to be present in some mice after acute exposure to 2 Gy photons or protons alone and in combination with LDR pre-exposure. The major adverse change was the presence of fibrosis-like lesions consisting of connective tissue components, ECM, and collagen in some acute and dual irradiation mice at both time points post-irradiation (Figure 1). Masson trichrome staining of lung sections to detect collagen deposition (blue color in Figure 2) showed more abundant collagen accumulated in alveolar spaces and at the sites surrounding vascular vessels or bronchioles in samples from Photon, Proton, LDR + Photon, and LDR + Proton groups as compared to the control and LDR samples.

\section{Gene expression profiles in irradiated groups compared to 0 Gy}

mRNA levels of 84 relevant genes in the lungs were compared between photon and proton groups $v s$. the control on days 21 and 56. In addition, results from each of the groups receiving either photons or protons alone were also compared with their respective counterparts that were pre-exposed to LDR $\gamma$-rays. Table 1 presents the official symbol and brief description of the affected genes in the irradiated mice compared to $0 \mathrm{~Gy}(\geq 1.5$-fold difference, $P<0.05)$. The actual fold-change for these 


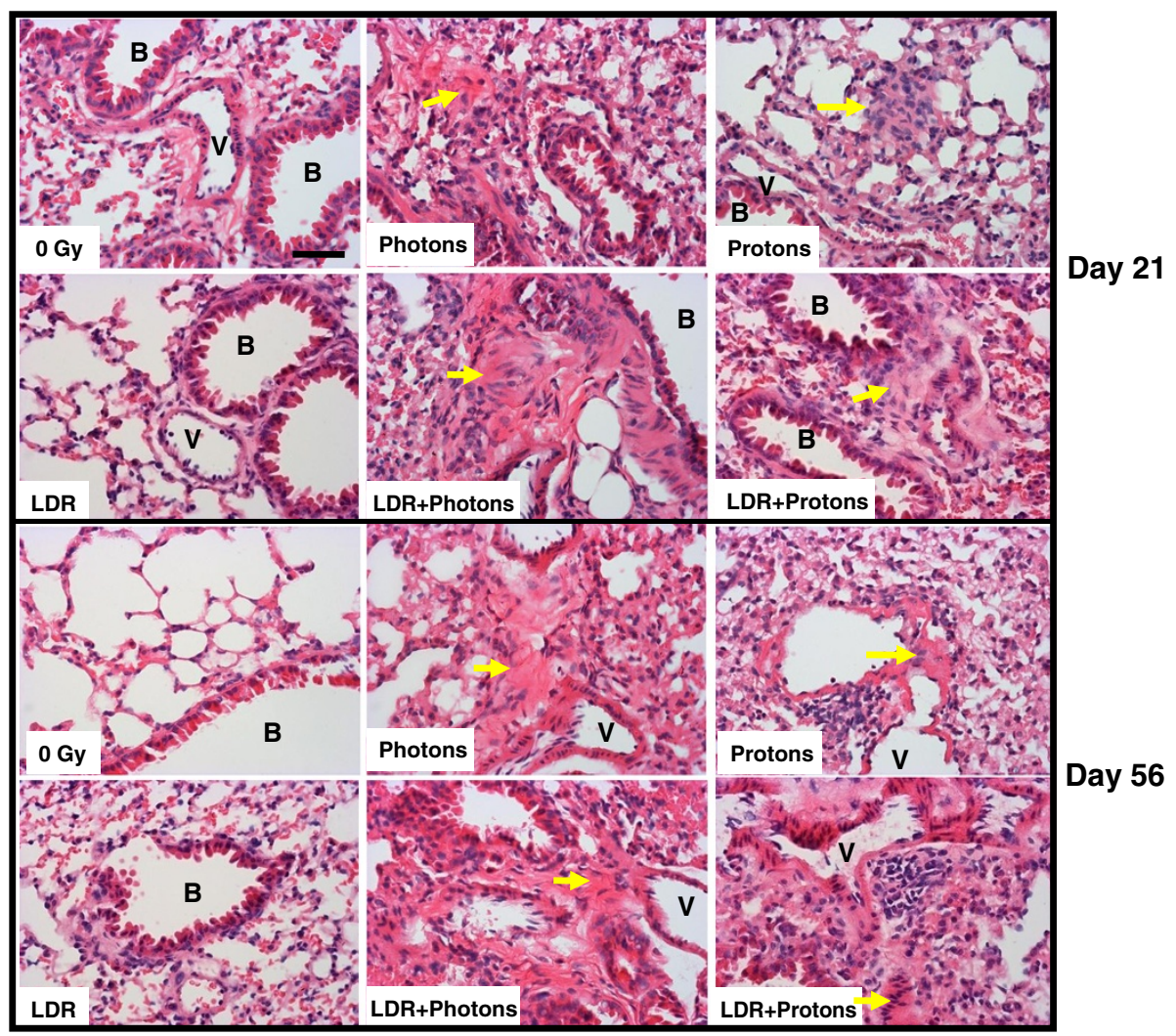

Figure 1 Photomicrographs of representative histopathological profiles. Sections of mouse lung tissue were paraffin-embedded postirradiation and stained with hematoxylin and eosin in each cohort. Yellow arrows show fibrosis-like changes comprised of connective tissue and extracellular matrix present in samples from 0 Gy control and irradiated mice. B, bronchioles; $V$, vascular vessels. Magnification $\times 400$, Bar $=20 \mu m$.

genes is shown in Table 2. We selected the 1.5-fold cutoff because there is no convincing evidence that a $>2$-fold difference always has a greater biological impact than a $<2$-fold difference; indeed, there is growing consensus that significant modulations that are $<2$-fold should be presented. Overall, more genes were affected by protons alone than by photons at both time points post-irradiation (11 vs. 6 on day 21 and 14 vs. 8 on day 56). Further analysis showed that all affected genes were up-regulated in the Proton group at both time points. Similarly, the majority of genes were also significantly upregulated by photons alone (Table 2).

Furthermore, the data showed that pre-exposure to LDR $\gamma$-rays increased the number of affected genes compared to acute photons alone ( 16 vs. 6 on day 21 and 11 vs. 8 on day 56). In the LDR + Photon group, $100 \%$ and about $91 \%$ of the affected genes were upregulated on days 21 and 56, respectively. Unlike the effect of LDR preexposure on response to subsequent 2 Gy photons, only one more gene was affected in the LDR + Proton group on day 21 as compared to protons alone (12 vs. 11). Surprisingly, only $50 \%$ of the genes that were modified by protons alone were affected in the LDR + Proton group on day 56 (7 vs. 14). More importantly, LDR pre-exposure 'normalized' the expression of several genes that were up-/downregulated by acute delivery of either protons or photons (that is, the levels of up- or downregulated genes by acute radiation were similar to those of 0 Gy control due to LDR pre-exposure). At both time points of assessment, expression of three genes in the Photon group were equivalent to 0 Gy due to LDR pre-exposure. In the Proton group, four and 10 genes were 'normalized' on days 21 $(4 / 11)$ and $56(10 / 14)$. On the other hand, some genes that were up-/downregulated in the combination groups were equivalent to $0 \mathrm{~Gy}$ when acute photons or protons were delivered alone (Table 2).

Further analyses showed that eight common genes were significantly upregulated in both combination irradiation groups (8/16 in LDR + Photon and 8/12 in LDR + Proton) as compared with 0 Gy on day 21 (Table 2). In contrast, only itga4 was downregulated in both combination irradiation groups on day 56. When comparisons were performed between acute proton or photon delivery alone with their respective counterparts that were pre-exposed to LDR $\gamma$-rays, only three genes were affected by photons alone (3/6) versus LDR plus photons (3/16), and seven genes were upregulated by protons alone (7/11) versus LDR plus protons $(7 / 12)$ on day 21 . On day 56 , five genes 


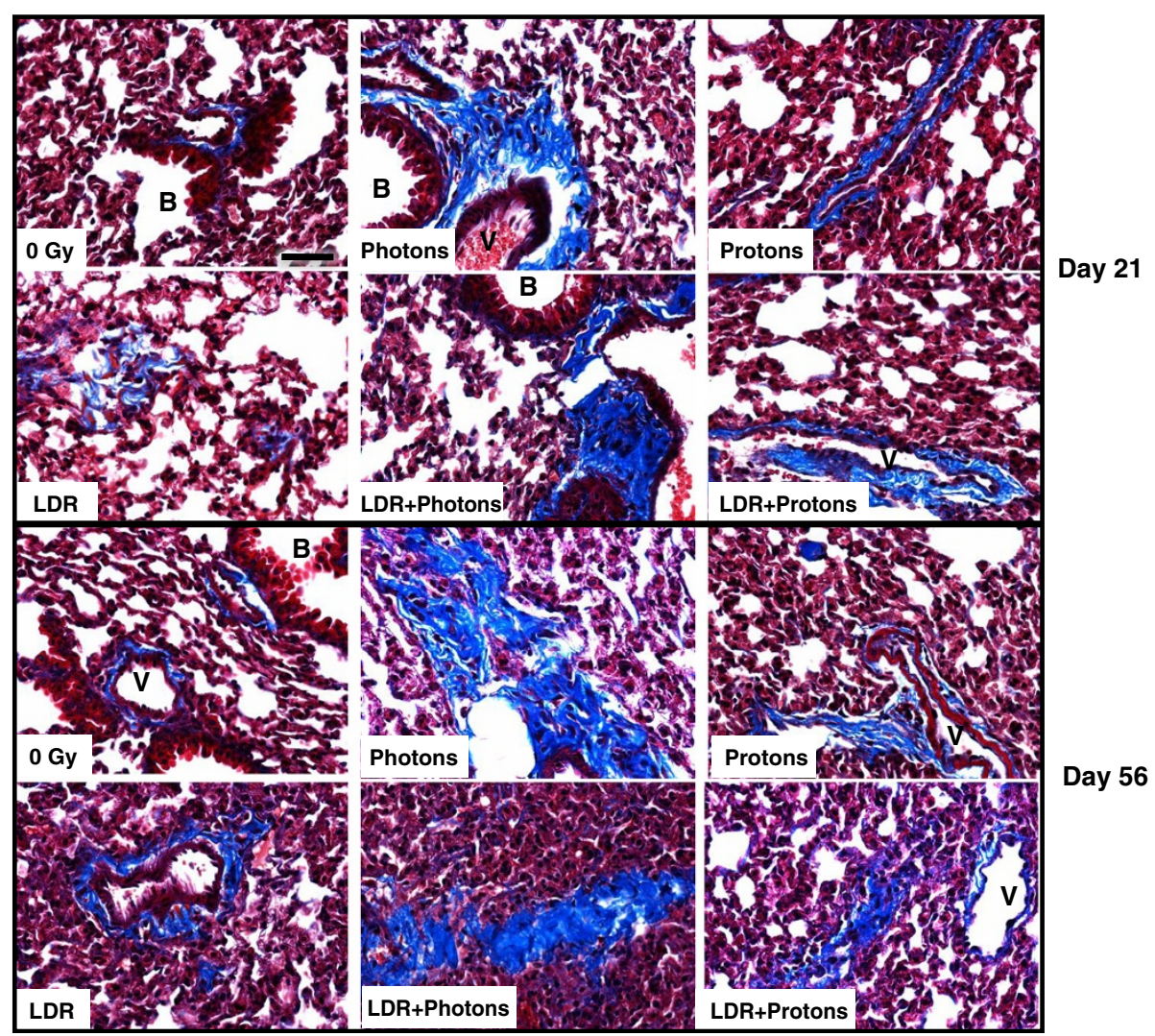

Figure 2 Masson trichrome staining of lung sections exhibits collagen deposition (blue). More abundant collagen is accumulated in alveolar space and at the sites surrounding vascular vessels or bronchioles in samples from Photon, Proton, LDR + Photon, and LDR + Proton groups as compared to the 0 Gy control and LDR samples. B, bronchioles; V, vascular vessels. Magnification × 400, Bar $=20 \mu \mathrm{m}$.

were modulated by acute photons alone as well as in combination with LDR; in the Proton and LDR + Proton groups, the same four genes were affected.

Among 26 genes that were modulated on day 21, only colla1, mmp14, and mmp15 were significantly upregulated by all radiation regimens. On day 56, however, colla 1 was upregulated only by proton radiation; mmp 14 and mmp 15 were 'normalized' in the LDR and LDR + Photon groups. Interestingly, in all four groups that received $\gamma$-ray photons (LDR, Photons, LDR + Photons, and LDR + Protons), the itga4 gene was significantly downregulated on day 56.

\section{Comparison of gene expression profiles among irradiated groups}

When comparison was made between 2 Gy protons versus 2 Gy photons, expression of six genes was significantly different in the Proton group on day 21 (five upregulated and one downregulated) and only one was upregulated on day 56 (Table 3). In addition, on day 21 there were three genes in the LDR + Photon group that were upregulated compared to the Photon group, whereas only one gene was upregulated in the LDR + Proton group versus protons alone (no genes were downregulated). By day 56, expression of three genes in the LDR + Photon group was different compared to the Photon group (two upregulated and one downregulated). In the LDR + Proton group at this same time point, expression of only one gene (downregulated) was different from proton radiation alone. We also include all genes that were not affected postirradiation (Table 4).

\section{Expression of profibrotic proteins}

Because the panel of 84 genes related to ECM and CAM did not include some other critical profibrotic factors, we also evaluated expression profiles of four major proteins: a cytokine frequently associated with fibrogenesis (TGF- $\beta 1$ ) and three other markers for mesenchymal cells or that are known to be involved in EMT.

TGF- $\beta 1$ is a critical cytokine. Western blotting showed that its expression was significantly enhanced in response to all radiation regimens at day 21 and to photons and both dual irradiations on day 56 as compared to the nonirradiated group $(P<0.05)$ (Figure 3$)$.

E-cadherin expressed in epithelial cells is responsible for cell-cell adhesion. Statistical analysis of Western blotting showed that the mean ratios of this adhesion molecule to 


\section{Table 1 Symbols and description for all significantly modulated genes in irradiated groups compared to the 0 Gy control group}

\begin{tabular}{|c|c|}
\hline Symbol & Name and gene category \\
\hline & Cell adhesion molecules \\
\hline$c d 44$ & CD44 antigen \\
\hline$c d h 1$ & Cadherin 1 \\
\hline cdh3 & Cadherin 2 \\
\hline $\operatorname{ctgf}$ & Connective tissue growth factor \\
\hline$f n 1$ & Fibronectin 1 \\
\hline hapln1 & Hyaluronan \& proreoglycan link protein 1 \\
\hline itga2 & Integrin alpha 2 \\
\hline itga3 & Integrin alpha 3 \\
\hline itga4 & Integrin alpha 4 \\
\hline Itgav & Integrin alpha v \\
\hline Itgax & Integrin alpha $x$ \\
\hline itgb4 & Integriin beta 4 \\
\hline ncam 1 & Neural cell adhesion molecule 1 \\
\hline ncam2 & Neural cell adhesion molecule 2 \\
\hline pecam1 & platelet/endothelial cell adhesion molecule 1 \\
\hline sele & Selectin, endothelial cell \\
\hline sell & Selectin, lymphocyte \\
\hline selp & Selectin, platelet \\
\hline \multirow[t]{2}{*}{$\operatorname{tgfbi}$} & Transforming growth factor, beta induced \\
\hline & Extracellular matrix proteins/proteinases \\
\hline adamts1 & $\begin{array}{l}\text { A disintegrin \& metallopeptidase with thrombospondin type I } \\
\text { motif } 1\end{array}$ \\
\hline adamts5 & $\begin{array}{l}\text { A disintegrin \& metallopeptidase with thrombospondin type I } \\
\text { motif } 5\end{array}$ \\
\hline collal & Collagen, type I, alpha 1 \\
\hline $\mathrm{col} 4 \mathrm{a} 3$ & Collagen, type IV, alpha 3 \\
\hline col5al & Collagen, type V, alpha 1 \\
\hline lama2 & Laminin, alpha 2 \\
\hline lama3 & Laminin, alpha 3 \\
\hline lamb3 & Laminin, beta 3 \\
\hline lamcl & Laminin, gamma 1 \\
\hline$m m p 2$ & Matrix metallopeptidase 2 \\
\hline mmp7 & Matrix metallopeptidase 7 \\
\hline mmp8 & Matrix metallopeptidase 8 \\
\hline mmp11 & Matrix metallopeptidase 11 \\
\hline mmp13 & Matrix metallopeptidase 13 \\
\hline mmp14 & Matrix metallopeptidase 14 \\
\hline mmp15 & Matrix metallopeptidase 15 \\
\hline timp1 & Tissue inhibitor of metalloproteinase 1 \\
\hline timp3 & Tissue inhibitor of metalloproteinase 3 \\
\hline the & Tenascin C \\
\hline
\end{tabular}

$\beta$-actin were significantly reduced in samples from the two acutely irradiated and LDR + Photon groups at both time points and in the LDR + Proton group on day 56 post-irradiation $(P<0.05)$ (Figure 3$)$.

Slug is a marker for EMT. It is involved in E-cadherin repression and also has antiapoptotic activity. Western blotting did not reveal marked enhancement or decrease in expression of this protein between groups.

$\alpha$-SMA is expressed only in mesenchymal cells that produce collagen and ECM. Western blotting showed that $\alpha$-SMA was significantly increased in all irradiated mice at both time points except on day 21 in the group that received LDR radiation alone (Figure 3).

\section{Discussion}

The lung is dynamically remodeled in response to injury, in which the change in ECM compositions can lead to either healthy or impaired regeneration. The tissue integrity and cell-cell or cell-matrix communications rely on cell adhesion molecules. Since protons and photons are two different forms of radiation, the biological effects generated by them are likely to be different. In this study, the changes in histology indicated that both types of radiations can induce profibrotic responses. Increased deposition of collagen in the lungs from irradiated animals (Figures 1 and 2) implies that activation of collagen producing cells is accelerated, leading to fibrosis-like change. Many studies have shown that low-dose radiation can induce radioadaptation that renders cells more resistant to a subsequent acute radiation event [20]. In this study, accumulation of more abundant collagen in both groups that received dual irradiation indicates that pre-exposure to LDR $\gamma$-rays did not render normal lung tissue more resistant to excessive production of this protein caused by acute radiation exposure.

In the present study, the differences between protons and photons in modulating expression of the genes related to ECM or CAM indicated that sensitivity of these genes to the two types of acute radiation regimens was different. More genes were affected by protons than by photons at both time points, suggesting that these relevant genes are more susceptible to protons. The markedly higher number of genes that were upregulated in the LDR + Photon group at both time points compared to the one that received only acute photons (Table 2) indicates that the protracted lowdose priming with $\gamma$-rays triggered mechanisms that rendered genes more responsive to acute photons. Only three genes (col1a1, $m m p-14$, and $m m p-15$ ) were upregulated in all irradiated groups on day 21, indicating that sensitivity of most genes was dependent on the type of radiation regimen. Colla1 encodes one of the markers for mesenchymal cell lineage. In addition, overexpression of matrix metalloproteinase (MMP) family members such as MMP-14 and MMP-15 is a consequence of perturbation of the balance 
Table 2 Genes with $\geq 1.5$-fold difference and $P<0.05$ compared to $0 \mathrm{~Gy}$ on day 21 and 56 post-irradiation

\begin{tabular}{|c|c|c|c|c|c|}
\hline Day 21 & $\begin{array}{c}2 \mathrm{~Gy} \\
\text { photons }\end{array}$ & $\begin{array}{c}2 \mathrm{~Gy} \\
\text { protons }\end{array}$ & LDR & $\begin{array}{l}\text { LDR + } 2 \text { Gy } \\
\text { photons }\end{array}$ & $\begin{array}{c}\mathrm{LDR}+2 \mathrm{~Gy} \\
\text { protons }\end{array}$ \\
\hline adamts5 & - & - & -1.58 & - & - \\
\hline cdh3 & - & - & -2.49 & - & - \\
\hline$c d 44$ & - & 1.94 & - & 1.88 & 1.67 \\
\hline collal & 1.82 & 2.40 & 2.28 & 2.52 & 1.58 \\
\hline $\mathrm{col} / 4 a_{3}$ & - & - & - & 1.69 & 1.61 \\
\hline col5al & - & - & - & 1.81 & 1.60 \\
\hline$f n 1$ & - & - & - & 1.53 & - \\
\hline hapln1 & - & 1.96 & - & - & 1.87 \\
\hline itga2 & - & 1.51 & - & 1.57 & - \\
\hline itga3 & - & - & - & 1.61 & - \\
\hline Itgav & - & 1.63 & - & 1.53 & 1.57 \\
\hline $\operatorname{ltg} a x$ & - & - & - & 1.53 & - \\
\hline lama2 & 1.71 & - & - & - & - \\
\hline lama3 & - & - & - & 1.77 & - \\
\hline lamb3 & - & 1.62 & - & - & 1.79 \\
\hline mmp2 & - & - & -1.62 & - & - \\
\hline$m m p 7$ & -2.46 & - & - & - & - \\
\hline mmp11 & - & - & & - & 1.87 \\
\hline mmp14 & 1.61 & 1.63 & 1.62 & 1.94 & 1.59 \\
\hline mmp15 & 1.50 & 1.66 & 1.61 & 1.96 & 1.78 \\
\hline ncam2 & - & - & - & 2.11 & - \\
\hline selp & - & - & - & 1.56 & 1.56 \\
\hline $\operatorname{tgfbi}$ & - & - & - & - & -1.50 \\
\hline timp1 & 1.59 & 1.89 & - & - & - \\
\hline timp3 & - & 2.44 & - & 1.98 & - \\
\hline the & - & 1.75 & - & 1.61 & - \\
\hline Total & 6 & 11 & 6 & 16 & 12 \\
\hline
\end{tabular}

\begin{tabular}{cccccc}
$\begin{array}{c}\text { (26) } \\
\text { Day 56 }\end{array}$ & $\begin{array}{c}\text { 2 Gy } \\
\text { photons }\end{array}$ & $\begin{array}{c}\text { 2 Gy } \\
\text { protons }\end{array}$ & LDR & $\begin{array}{c}\text { LDR + 2 Gy } \\
\text { photons }\end{array}$ & $\begin{array}{c}\text { LDR + 2 Gy } \\
\text { protons }\end{array}$ \\
\hline adamts1 & - & - & - & 1.57 & - \\
\hline cdh1 & - & - & - & 1.71 & - \\
\hline cdh3 & 2.97 & 4.02 & - & 3.98 & - \\
\hline cd44 & - & 1.66 & - & - & - \\
\hline col1a1 & - & 1.67 & - & - & 2.31 \\
\hline col4a3 & 1.64 & - & - & 1.69 & - \\
\hline ctgf & - & - & - & 1.70 & - \\
\hline itga2 & 1.54 & 1.72 & - & - & - \\
\hline itga4 & -1.63 & - & -1.82 & -1.52 & -2.09 \\
\hline itgax & - & 1.55 & - & - & - \\
\hline itgb4 & - & 1.86 & 1.74 & - & 1.71 \\
\hline lama2 & - & - & - & 1.74 & - \\
\hline lamb3 & - & 1.58 & - & - & - \\
\hline lamc1 & - & 1.60 & - & - & - \\
\hline mmp8 & - & - & - & 1.76 & - \\
\hline mmp13 & - & - & - & - & -2.21 \\
\hline & & & & & \\
\hline
\end{tabular}

Table 2 Genes with $\geq 1.5$-fold difference and $P<0.05$ compared to $0 \mathrm{~Gy}$ on day 21 and 56 post-irradiation (Continued)

\begin{tabular}{cccccc}
\hline mmp14 & 1.55 & 1.75 & - & - & 1.66 \\
\hline mmp15 & 1.54 & 1.79 & - & - & 1.56 \\
\hline ncam1 & - & 1.94 & - & - & - \\
\hline ncam2 & 2.41 & - & - & 3.6 & - \\
\hline pecam1 & - & - & - & 3.46 & - \\
\hline sele & - & - & 1.57 & - & - \\
\hline sell & - & - & - & - & -1.94 \\
\hline tgfbi & - & 1.56 & - & - & - \\
\hline timp3 & 3.70 & 4.00 & - & 4.10 & - \\
\hline thc & - & 1.56 & - & - & - \\
\hline Total & 8 & 14 & 3 & 11 & 7 \\
$(26)$ & & & & & \\
\hline
\end{tabular}

Gene expression in lung samples was determined using quantitative RT-PCT. The numbers represents the fold-changes based on each irradiated group versus control group.

,$- P$ value was $>0.05$ and/or relative fold-change was $<1.5$.

between synthesis and degradation of collagen and other ECM components [21]. MMP-14 is capable of proteolytic degradation of type I, II, and III collagens following the characteristic cleavage pathway [22]. MMP-14 also cleaves many membrane-anchored proteins such as $\mathrm{E}$ - and $\mathrm{N}$ cadherin, integrins, CD44 (a hyaluronan receptor), and several cell surface proteoglycans and their receptors [22]. MMP-15 is a ubiquitously expressed enzyme with largely overlapping substrate specificity with MMP-14 [23]. The profibrotic change in histopathology post-irradiation indicates that all radiation regimens used in the present study resulted in perturbation of normal tissue remodeling and excessive production of collagen. The overproduction of collagen and/or ECM may initiate transcription of genes that downregulate MMP, that is, MMP inhibitor genes, timp-1 and/or timp-3. Of course, the final fate of lung status after irradiation depends on whether normal or aberrant repair takes place, a process that is largely determined by cell microenvironment.

In addition, $c d 44$ and itgav (encoding a $\alpha v$ subunit of integrin) were significantly upregulated in the Proton and both combination groups on day 21. CD44 mediates cell-cell and cell-matrix interactions through its affinity for hyaluronic acid (HA), and also other ligands such as collagens and MMPs. Therefore, altered expression or dysfunction of CD44 may cause pathogenic phenotypes. The itgav gene encodes a receptor for many ligands, such as fibronectin, fibrinogen, laminin, and MMP-2. Moreover, the $\alpha \mathrm{v}$ subunit can also activate TGF- $\beta 1$ when it is associated with a $\beta 6$ or $\beta 8$ subunit on airway epithelial cells, leading to poor wound healing [24]. When cell surface proteins like E-cadherin and integrins that mediate epithelial connections to neighboring cells and the 
Table 3 Genes with $\geq 1.5$-fold and $P<0.05$ between irradiated groups on days 21 and 56 post-irradiation

\begin{tabular}{|c|c|c|c|c|}
\hline Day 21 & $\begin{array}{c}\text { Protons } \\
\text { vs. } \\
\text { Photons }\end{array}$ & $\begin{array}{l}\text { LDR + } \\
\text { Photons vs. } \\
\text { Photons }\end{array}$ & $\begin{array}{l}\text { LDR + } \\
\text { Protons vs. } \\
\text { Protons }\end{array}$ & $\begin{array}{c}\text { LDR + Protons } \\
\text { vs. LDR + } \\
\text { Photons }\end{array}$ \\
\hline colla1 & - & - & -1.52 & -1.6 \\
\hline itgb4 & -1.54 & - & - & - \\
\hline lama2 & 1.86 & 1.56 & - & - \\
\hline mmpla & 1.50 & - & - & 1.55 \\
\hline ncam2 & 2.04 & 2.91 & - & - \\
\hline timp3 & 2.17 & 1.75 & -2.33 & - \\
\hline vcam 1 & 1.94 & - & - & - \\
\hline Total (7) & 6 & 3 & 2 & 2 \\
\hline Day 56 & $\begin{array}{l}\text { Protons } \\
\text { vs. } \\
\text { Photons }\end{array}$ & $\begin{array}{l}\text { LDR + } \\
\text { Photons vs. } \\
\text { Photons }\end{array}$ & $\begin{array}{l}\text { LDR + } \\
\text { Protons vs. } \\
\text { Protons }\end{array}$ & $\begin{array}{l}\text { LDR + Protons } \\
\text { vs. LDR + } \\
\text { Photons }\end{array}$ \\
\hline adamts 1 & - & 1.50 & - & - \\
\hline collar & - & -1.51 & - & 2.52 \\
\hline $\operatorname{ctg} f$ & - & 1.5 & - & - \\
\hline$m m p 9$ & - & - & - & -1.64 \\
\hline ncam2 & - & - & - & -2.36 \\
\hline sell & - & - & -1.97 & - \\
\hline sgce & - & - & - & -1.68 \\
\hline spock1 & 2.09 & - & - & - \\
\hline Total (8) & 1 & 3 & 1 & 4 \\
\hline
\end{tabular}

Gene expression in lung samples was determined using quantitative RT-PCT. The numbers represents the fold-changes based on each irradiated group versus control group.

,$- P$ value was $>0.05$ and/or relative fold-change was $<1.5$.

basement membrane, respectively, are replaced by $\mathrm{N}$ cadherin and ectopic integrins, the cell may be primed for the mesenchymal phenotype by more transient adhesive properties [25]. In addition, we also noted that the two combined radiation groups had more upregulated integrin genes that participate in cell-matrix adhesion and/or are collagen and ECM structure constituents. This was especially evident on day 21 and suggests that the combined irradiation may also cause dysregulated repair. In addition, significant downregulation of itga4 by $\gamma$-rays, either at a high dose or a low dose, indicates that this gene was highly sensitive to $\gamma$-ray photons.

Two collagen genes (col4a 3 and colsa1) and selp (Pselectin, platelet) that were significantly upregulated on day 21 after protracted exposure to LDR $\gamma$-rays combined with acute radiation further indicates that synthesis of collagen may be enhanced. P-selectin is an inflammatory adhesion molecule found on endothelial cells and platelets. It enables the recruitment of leukocytes to the endothelium and activates platelets. Platelets contain a plethora of growth factors and cytokines, including high concentrations of TGF- $\beta$ [26] that is well known to be a strong inducer of fibrogenesis. Thus, upregulation of selp can lead to the release of more cytokines and growth
Table 4 Among 84 analyzed genes that were not affected by radiation exposure

\begin{tabular}{|c|c|}
\hline Symbol & Name \\
\hline adamts2 & $\begin{array}{l}\text { A disintegrin-like and metallopeptidease with } \\
\text { thrombospondin type } 1 \text { motif, } 2\end{array}$ \\
\hline adamts8 & $\begin{array}{l}\text { A disintegrin-like and metallopeptidease with } \\
\text { thrombospondin type } 1 \text { motif, } 8\end{array}$ \\
\hline cdh1 & cadherin 1 \\
\hline cdh4 & cadherin 4 \\
\hline ctnnal & catenin (cadherin associated protein), alpha 1 \\
\hline ctnna2 & catenin (cadherin associated protein), alpha 2 \\
\hline ctnnb1 & catenin (cadherin associated protein), beta 1 \\
\hline cntn 1 & contactin 1 \\
\hline col2al & collagen, Type II, alpha 1 \\
\hline$\overline{c o l 3 a 1}$ & collagen, Type III, alpha 1 \\
\hline$\overline{c o / 4 a 1}$ & collagen, Type IV, alpha 1 \\
\hline $\mathrm{col} / 4 a 2$ & collagen, Type IV, alpha 2 \\
\hline col6al & collagen, Type Vl, alpha 1 \\
\hline$\overline{\mathrm{ecm} 1}$ & extracellular matrix protein 1 \\
\hline emifin1 & elastin microfibril interfacer 1 \\
\hline entpd1 & Ectonucleoside triphosphate diphosphohydrolase 1 \\
\hline$\overline{f b l n 1}$ & fibulin 1 \\
\hline hapln1 & hyaluronan and proteoglycan link protein 1 \\
\hline$\overline{H C}$ & hemolytic complement \\
\hline icaml & intercellular adhesion molecule 1 \\
\hline itga5 & integrin alpha 5 \\
\hline Itgae & integrin alpha e \\
\hline Itgal & integrin alpha I \\
\hline Itgam & integrin alpha $\mathrm{m}$ \\
\hline itgbl & integrin beta 1 \\
\hline itgb2 & integrin beta 2 \\
\hline itgb3 & integrin beta 3 \\
\hline itgb4 & integrin beta 4 \\
\hline lama1 & laminin, alpha 1 \\
\hline lamb2 & laminin, beta 2 \\
\hline lamb3 & laminin, beta 3 \\
\hline$\overline{m m p 3}$ & matrix metallopeptidase 3 \\
\hline$\overline{\text { postn }}$ & periostin, osteoblast specific factor \\
\hline sparc & secreted acidic cysteine rich glycoprotein \\
\hline spp1 & secreted phosphoprotein 1 \\
\hline syt1 & synaptotagmin 1 \\
\hline thbs1 & thrombospondin 1 \\
\hline thbs2 & thrombospondin 2 \\
\hline thbs3 & thrombospondin 3 \\
\hline$\overline{v c a n}$ & Versican \\
\hline$\overline{v t n}$ & Vitronectin \\
\hline
\end{tabular}




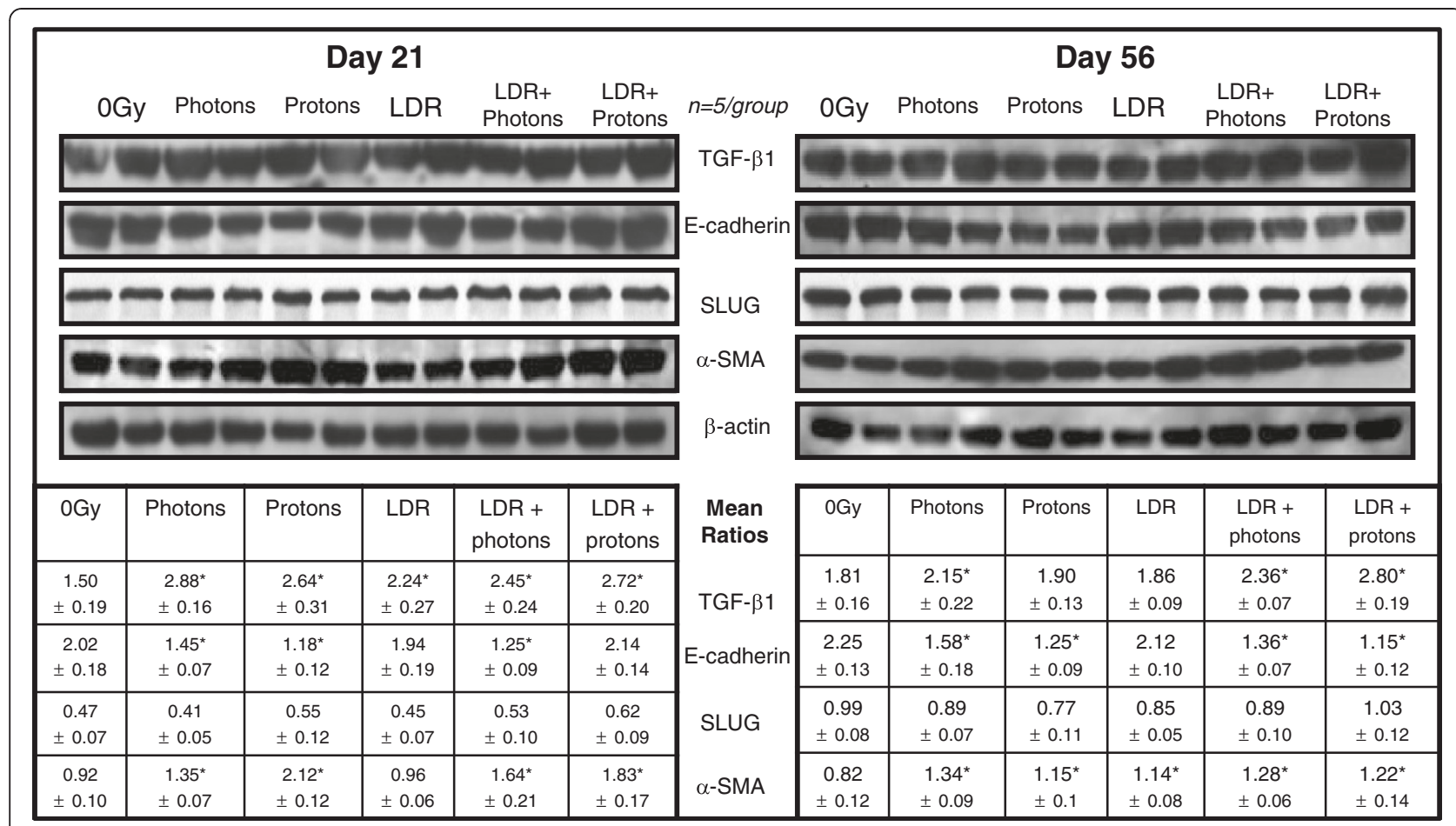

Figure 3 Representative blots of four profibrotic mediators in lung tissue. Expression of the proteins (five samples/group) and $\beta$-actin was determined by Western blotting. The tables show the ratios of target bands to $\beta$-actin corresponding to western blots and analyzed with two-way ANOVA. ${ }^{*} P<0.05$ compared to 0 Gy at the corresponding time point; means +/- standard error of the means (SEM) are shown. LDR, low-dose/low-dose-rate.

factors from activated platelets, potentially promoting a mesenchymal phenotype [27].

The enhanced appearance of major profibrotic proteins in response to the radiation regimens also indicates epithelial early injury. Here we noted excess production of collagen and ECM molecules after acute and combination irradiation. It is well established that TGF- $\beta 1$ promotes differentiation of fibroblasts into activated myofibroblasts, enhances collagen synthesis, and reduces collagen degradation by downregulating proteases and upregulating protease inhibitors [28]. Increased expression of TGF- $\beta 1$ in the samples from irradiated groups at both time points indicates that the mechanisms responsible for production of this cytokine are very sensitive to ionizing radiation, even low-dose-rate photons delivered over an extended time period.

Myofibroblasts are strongly associated with tissue repair and fibrosis. $\alpha$-SMA, a major marker of myofibroblasts, is linked to cell-cell adherence sites and cellmatrix anchorages, the latter being essential for contractile as well as biosynthetic functions. The changes in histology and collagen staining in the irradiated groups may partly result from transition of more myofibroblasts from other cell types, for example, epithelial or adult stem cells. TGF- $\beta 1$ is one of several profibrotic cytokines that activate myofibroblast progenitors [29]. As a result, excessive accumulation of collagen and ECM can occur. Reactive oxygen species (ROS) generated by radiation exposure are immediate activators of TGF- $\beta 1[30,31]$. Evidence suggests that once activated, myofibroblasts may not require continued paracrine stimulation by fibrogenic cytokines, relying instead on positive autocrine feedback [29].

E-cadherin is broadly expressed only by epithelial cells. It is also a key component of adhesion junctions that play an important role in maintenance of epithelial integrity [32]. In this study, low ratio of E-cadherin to $\beta$-actin bands indicates that this epithelial marker was sensitive to radiation. Low E-cadherin is associated with breakdown of epithelial integrity and also poor repair capacity.

Jayachandran et al. [33] showed that TGF- $\beta 1$ treatment increased the expression and nuclear accumulation of Slug, a transcription factor, in concert with induction of EMT in type II alveolar cells. However, in the present study, Slug expression was not markedly affected by ionizing radiation at the two time points of assessment, thereby implying that Slug protein, unlike TGF- $\beta 1$, E-cadherin, and $\alpha$-SMA, was not sensitive to irradiation. Further study will explore the expression of Slug gene post-irradiation.

\section{Conclusion}

This study provides new information on normal lung response to proton radiation. Both acute proton and 
photon radiation regimens induced overexpression of certain ECM/CAM genes and profibrotic mediators, leading to production of excess collagen and ECM. The present data also showed that the effect of protons on gene expression was more profound compared to photons. The differences in gene expression that were noted between the acutely irradiated groups are likely due to the different physical properties of protons and photons. Protons are particles with a positive electrical charge equal to that of electrons, whereas photons are a type of electromagnetic radiation consisting of elementary particles. Furthermore, pre-exposure to LDR $\gamma$-rays resulted in more modification in the gene profile when followed by acute photon irradiation compared to acute protons. These findings have implications related to human space exploration, as well as radiation exposure above normal on Earth. Future studies should include more time points and multiple doses after exposure to both forms of ionizing radiation. Furthermore, since fibrosis is an unlikely outcome after a 2 Gy dose as used here, future studies should include higher radiation doses localized to the lungs and longer intervals postirradiation to determine if a difference exists between photons and protons in ultimate outcome and if LDR pre-exposure has modifying effects.

\section{Methods}

\section{Animals and study design}

Wild-type C57BL/6 mice ( $n=120,8$ to 9-week-old female mice; Charles River Laboratories, Hollister, CA, USA) were maintained under standard vivarium conditions in a BioZone VentiRack ${ }^{\mathrm{TM}}$ (BioZone, Inc., Fort Mill, SC, USA). There were six groups: (1) 0 Gy; (2) Photons; (3) Protons; (4) LDR; (5) LDR + Photons; and (6) LDR + Protons. Subsets/groups were euthanized in $100 \% \mathrm{CO}_{2}$ on days 21 and 56 post-irradiation. The protocol was approved by the Loma Linda University (LLU) Institutional Animal Care and Use Committee prior to initiation and followed all recommendations in the Guide for the Care and Use of Laboratory Animals of the National Institutes of Health. The mice were monitored daily by expert LLU animal care personnel and the investigators. All efforts were made to ensure little or no suffering.

\section{Irradiation procedures}

For LDR priming, mice were irradiated using ${ }^{57} \mathrm{Co}$ plates (AEA Technology, Burlington, MA, USA) placed immediately beneath their cages (one plate/two cages in BioZone rack). A total dose of $0.01 \mathrm{~Gy}$ was delivered at $0.03 \mathrm{cGy} / \mathrm{h}$ to a maximum of five mice/large cage. Since $\gamma$-rays easily penetrate for long distances through many materials (major exceptions being lead and concrete), the dose for each individual animal was not determined. Dose confirmation, however, was performed using several thermoluminescent dosimeters (TLD) at various locations per cage. The data showed that dose uniformity was $\pm 5 \%$.

For acute photon and proton irradiation, mice were placed individually into polystyrene aerated cubicles and irradiated to 2 Gy once within a very short period of time. Photon radiation was delivered using ${ }^{60} \mathrm{Co} \gamma$-rays (0.8 Gy/min; Eldorado Model G, Atomic Energy of Canada Ltd, Ottawa, Canada). Proton irradiation was done in the Proton Treatment and Research Center at Loma Linda University Medical Center; an average dose rate of $0.9 \mathrm{~Gy} / \mathrm{min}$ and $230 \mathrm{MeV}$ energy was used. Different groups received acute photon or proton radiation alone or within 1-2 $\mathrm{h}$ after protracted exposure to LDR $\gamma$-rays. Additional details on set-up and dosimetry have been previously published [20].

\section{Analysis of gene expression by quantitative reverse transcriptase-polymerase chain reaction (RT-PCR)}

Immediately after sacrifice, the right lungs were frozen in liquid nitrogen ( $n=5 \mathrm{mice} /$ group/time point) and kept at $-80^{\circ} \mathrm{C}$ until analysis. The 84 relevant genes were assessed using $\mathrm{RT}^{2}$ Profiler $^{\text {TM }}$ PCR Array PAMM-013 (SuperArray BioSciences, Frederick, MD, USA) to compare mRNA levels of ECM and CAM in lung tissue between irradiated groups and the 0 Gy control. To determine the effect of LDR $\gamma$-rays on response to acute radiation, gene expression levels in the LDR + Photon and LDR + Proton groups were compared to the levels obtained for their counterparts that received acute radiation alone. RNA extraction, RT-PCR, and its data analyses were performed by SuperArray BioSciences. Genes with $\geq 1.5$-fold difference in expression and $P<0.05$ in the various group comparisons are emphasized. The $\Delta \Delta \mathrm{Ct}$ method used in PCR array of this study is widely accepted and known as a valid method for relative quantification of real-time PCR data.

\section{Histopathology}

After harvest, the left lungs were formalin-fixed, paraffin-embedded, and sections (5- $\mu \mathrm{m}$ thick) were prepared for standard hematoxylin/eosin (H\&E) and Masson trichrome collagen staining. The changes in histology were assessed under a light microscope.

\section{Masson Trichrome collagen staining}

Briefly, deparaffinzed sections were pretreated in Bouin's fluid at $56^{\circ} \mathrm{C}$ for $1 \mathrm{~h}$ before they were stained with Weigert's Iron Hematoxylin, Biebrich Scarlet-Acid Fuchsin solution and Aniline Blue Stain Solution. Finally, 1\% Acetic Acid solution was used to remove non-specific staining. After this procedure, the nuclei are stained black, cytoplasm and muscle fibers are displayed as red, and blue color represents collagen. The lung consists of a great number of alveoli and its expansion is not uniform throughout. Although, in this study, whole-mount sections of the lungs 
were not scanned for quantification of collagen, we could identify the difference in relative amounts of collagen in lung tissue from the Trichrome stained sections under a microscope.

\section{Western blotting}

A total of $50 \mathrm{mg}$ of lung tissue from each mouse was homogenized in $50 \mu \mathrm{L}$ of RIPA lysis buffer (Sigma, St. Louis, MO, USA) containing protease inhibitors (Roche, Indianapolis, IN, USA), and then pelleted via centrifugation at $13,000 \mathrm{~g}$ at $4^{\circ} \mathrm{C}$. The protein concentration in supernatants was measured using the Coomassie Plus assay (Pierce, Rockford, IL, USA). Then, $25 \mathrm{mg}$ of protein was loaded in each well of the gel for electrophoresis prior to electroblotting proteins onto polyvinylidene fluoride (PVDF) membranes (Invitrogen, Carlsbad, CA, USA). In order to compare marker expression under the same condition, we loaded two of five samples from each group on the same gel with 12 wells. Six gels were used for a total of 60 specimens (five mice/group/time point). All membranes were incubated overnight with primary antibody at $4{ }^{\circ} \mathrm{C}$ following blocking non-specific binding sites in 5\% non-fat milk in Tris Buffered Saline (TBS) containing $0.1 \%$ Tween 20 . The same membranes after electroblotting were incubated separately with different primary antibodies that were used to detect the proteins with different size prior to treatment with the secondary antibody conjugated with horseradish peroxidase (HRP, Millipore, Temecula, CA, USA). However, when detecting different proteins with similar size, stripping buffer (2\% SDS, $62.5 \mathrm{mM}$ Tris- $\mathrm{HCl} \mathrm{pH}$ 6.7, $100 \mathrm{mM}$ 2-mercaptoethanol) was used to remove primary and secondary antibodies on the PVDF membrane before proceeding to detect another target. This stripping buffer removes antibodies from membranes very effectively. Nonetheless, every time the stripped membranes were incubated with second antibody to confirm that no previous primary antibody remained on the membranes prior to incubating them with a new primary antibody. Four rabbit anti-mouse primary polyclonal antibodies were used to identify transforming growth factor (TGF)- $\beta 1$ (recombinant full length inactive form), E-cadherin, Slug, and $\alpha$-SMA. $\beta$-actin, utilized as a housekeeping protein, was detected with polyclonal antibody. All antibodies were purchased from Abcam. The enhanced chemiluminescence (ECL) and film exposure method (GE Healthcare-Bio-Sciences Corp., Piscataway, NJ, USA) was used to display the bands on the membranes. We used the Biospectrum 310 MultiSpectral System (Ultra-Violet Products, Ltd., Upland, CA, USA) and the appropriate software to measure band intensity on the films. This device is able to select real size of individual target bands, thus eliminating as much background as possible.

\section{Statistical analysis}

Gene expression data were evaluated using Student's t-test, a well-accepted method for data obtained using the RT-PCR method described above. The ratios of target bands to $\beta$-actin obtained from Western blotting between each of the irradiated groups and 0 Gy at both time points was analyzed using two-way analysis of variance (ANOVA) followed by the Tukey test (Systat Software, Richmond, CA, USA).

\section{Abbreviations}

a-SMA: Alpha-smooth muscle actin; CAM: Cell adhesion molecules; ECM: Extracellular matrix; EMT: Epithelial-mesenchymal transition; Gy: Gray; IR: Ionizing radiation; LDR: Low-dose/Low-dose-rate; RILF: Radiation-induced lung fibrosis; RT-PCR: Reverse transcriptase-polymerase chain reaction; TGF- $\beta 1$ : Transforming growth factor-beta1.

\section{Competing interests}

No competing interests are declared by all authors.

\section{Authors' contributions}

JT and ST carried out the experiments and performed the statistical analyses reported in this study. JT and DSG conceived the study, participated in the design of the study, participated in its coordination, and drafted the manuscript. All authors read and approved the final manuscript.

\section{Acknowledgments}

The authors thank Melba L. Andres, Steven Rightnar, Celso Perez, Jiayan Wang, Pete Koss, Gordon Harding and Drs. Michael J. Pecaut, Asma Rizvi, and Adeola Y. Makinde for valuable assistance in many aspects of this research. The study was supported by the Low Dose Radiation Research Program, Office of Science, U.S. Department of Energy (DoE) Grant No. DE-FG0207ER64345 and the Department of Radiation Medicine at Loma Linda University Medical Center.

\section{Author details}

'Department of Radiation Medicine, Radiation Research Laboratories and Department of Basic Sciences, Loma Linda University, Loma Linda, California, USA. ${ }^{2}$ Department of Otolaryngology, Loma Linda University Medical Center, Loma Linda, California 92354, USA. ${ }^{3}$ Department of Pathological Anatomy,

Nantong University, Nantong, China.

Received: 14 November 2012 Accepted: 9 January 2013

Published: 4 February 2013

\section{References}

1. Paganetti $\mathrm{H}$ : Significance and implementation of RBE variations in proton beam therapy. Tech Cancer Res Treat 2003, 2:413-426.

2. Ohnishi $\mathrm{K}$, Ohnishi $\mathrm{T}$ : The biological effects of space radiation during long stays in space. Biol Sci Space 2004, 18:201-205.

3. Smart DF, Shea MA: A review of solar proton events during the 22nd solar cycle. Adv Space Res 2000, 30:1033-1044.

4. West JB, Elliott AR, Guy HJ, Prisk GK: Pulmonary function in space. JAMA 1997, 277:1957-1961.

5. Prisk GK: The lung in space. Clin Chest Med 2005, 26:415-438

6. Carver JR, Shapiro CL, Ng A, Jacobs L, Schwartz C, Virgo KS, Hagerty KL, Somerfield MR, Vaughn DJ, ASCO Cancer Survivorship Expert Panel: American Society of Clinical Oncology clinical evidence review on the ongoing care of adult cancer survivors: Cardiac and pulmonary late effects. J Clin Oncol 2007, 25:3991-4008.

7. Kong FM, Ten Haken R, Eisbruch A, Lawrence TS: Non-small cell lung cancer therapy-related pulmonary toxicity: an update on radiation pneumonitis and fibrosis. Semin Oncol 2005, Suppl 3:42-54.

8. Bush DA: Proton radiation therapy for lung cancer: is there enough evidence? Oncology 2010, 24:1052-1057.

9. Ishikura S: Optimal radiotherapy for non-small-cell lung cancer: current progress and future challenges. Gen Thorac Cardiovasc Surg 2012, 60:127-131.

10. Tian J, Pecaut MJ, Coutrakon GB, Slater JM, Gridley DS: Response of extracellular matrix regulators in mouse lung after exposure to photons, 
protons and simulated solar particle event protons. Radiat Res 2009, 172:30-41.

11. Crosby LM, Waters CM: Epithelial repair mechanisms in the lung. Am J Physiol Lung Cell Mol Physiol 2010, 298:L715-L731.

12. Tsoutsou PG, Koukourakis MI: Radiation pneumonitis and fibrosis: mechanisms underlying its pathogenesis and implications for future research. Int J Radiat Oncol Biol Physiol 2006, 6:1281-1293.

13. Paine R III, Ward PA: Cell adhesion molecules and pulmonary fibrosis. Am J Med 1999, 107:268-279.

14. Tian J, Pecaut MJ, Slater JM, Gridley DS: Spaceflight modulates expression of extracellular matrix, adhesion, and profibrotic molecules in mouse lung. J Appl Physiol 2010, 108:162-171.

15. Sime PJ, O'Reilly KM: Fibrosis of the lung and other tissues: new concepts in pathogenesis and treatment. Clin Immunol 2001, 99:308-319.

16. Wynn TA: Cellular and molecular mechanisms of fibrosis. J Pathol 2008 214:199-210.

17. Comijn J, Berx G, Vermassen P, Verschueren $K$, van Grunsven L, Bruyneel $E$, Mareel M, Huylebroeck D, van Roy F: The two-handed E box binding zinc finger protein SIP1 downregulates E-cadherin and induces invasion. Mol Cell 2001, 7:1267-1278

18. Hajra KM, Chen DY, Fearon ER: The SLUG zinc-finger protein represses E-cadherin in breast cancer. Cancer Res 2002, 62:1613-1618.

19. Bhattacharjee $D$, Ito $A$ : Deceleration of carcinogenic potential by adaptation with low dose gamma irradiation. In Vivo 2001, 15:87-92.

20. Gridley DS, Williams JR, Slater JM: Low-dose/low-dose-rate radiation: a feasible strategy to improve cancer radiotherapy? Cancer Thera 2005, 3:105-130.

21. Lagente V, Manoury S, Nenan C, Le Quement C, Martin-Chouly C, Boichot E: Role of matrix metalloproteinases in the development of airway inflammation and remodeling. Braz J Med Biol Res 2005, 38:1521-1530.

22. d'Ortho MP, Will H, Atkinson S, Butler G, Messent A, Gavrilovic J, Smith B, Timpl R, Zardi L, Murphy G: Membrane-type matrix metalloproteinases 1 and 2 exhibit broad-spectrum proteolytic capacities comparable to many matrix metalloproteinases. Eur J Biochem 1997, 250:751-757.

23. Barbolina MV, Stack MS: Membrane type 1-matrix metalloproteinase: substrate diversity in pericellular proteolysis. Semin Cell Dev Biol 2008, 19:24-33.

24. Neurohr C, Nishimura SL, Sheppard D: Activation of transforming growth factor-beta by the integrin alphvbeta8 delays epithelial wound closure. Am J Respir Cell Mol Biol 2006, 35:252-259.

25. Micalizzi DS, Farabaugh SM, Ford HL: Epithelial-mesenchymal transition in cancer: parallels between normal development and tumor progression. J Mammary Gland Biol Neoplasia 2010, 15:117-134.

26. Assoian RK, Komoriya A, Meyers CA, Miller DM, Sporn MB: Transforming growth factor-beta in human platelets. Identification of a major storage site, purification, and characterization. J Biol Chem 1983, 258:7155-7160.

27. Labelle M, Begum S, Hynes RO: Direct signaling between platelets and cancer cells induces an epithelial-mesenchymal-like transition and promotes metastasis. Cancer Cell 2011, 20:576-590.

28. Kelly M, Kolb M, Bonniaud P, Gauldie J: Re-evaluation of fibrogenic cytokines in lung fibrosis. Cur Pharmaceut Design 2003, 9:39-49.

29. Yarnold J, Brotons MCV: Pathogenetic mechanisms in radiation fibrosis. Radiat Oncol 2010, 97:149-161.

30. Barcellos-Hoff MH, Dix TA: Redox-mediated activation of latent transformation growth factor beta 1. Mol Endocrinol 1996, 10:1077-1083.

31. Jobling MF, Mott JD, Finnegan MT, Jurukovski V, Erickson AC, Walian PJ, Taylor SE, Ledbetter S, Lawrence CM, Rifkin DB, Barcellos-Hoff MH: Isoform-specific activation of latent transformation growth factor beta (LTGF-beta) by reactive oxygen species. Radiat Res 2006, 166:839-848.

32. Larue L, Bellacosa A: Epithelial-mesenchymal transition in development and cancer: role of phosphatidylinositol 3' kinase/AKT pathways. Oncogene 2005, 24:7443-7454.

33. Jayachandran A, Königshoff M, Yu H, Rupniewska E, Hecker M, Klepetko W, Seeger W, Eickelberg O: SNAI transcription factors mediate epithelialmesenchymal transition in lung fibrosis. Thorax 2009, 64:1053-1061.

doi:10.1186/1755-1536-6-4

Cite this article as: Tian et al:: Comparison of acute proton, photon, and low-dose priming effects on genes associated with extracellular matrix and adhesion molecules in the lungs. Fibrogenesis \& Tissue Repair 2013 6:4.

\section{Submit your next manuscript to BioMed Central and take full advantage of:}

- Convenient online submission

- Thorough peer review

- No space constraints or color figure charges

- Immediate publication on acceptance

- Inclusion in PubMed, CAS, Scopus and Google Scholar

- Research which is freely available for redistribution 